tailored questionnaire was administered as Visual Analogue Scale (VAS) during monitoring visits, to evaluate intensity of pain. Furthermore quality of life was monitored through Short Form (36) Health Survey.

Results: Mean age was similar in the two study groups with values of $45.4 \pm 5.6$ years and $46.1 \pm 4.1$ respectively. In the patients treated with Lecoxen cream, the reduction of lesion size was significantly higher $(70 \%-75 \%)(p<0,001)$ in comparison with those registered in group II $(40-45 \%)(p<0,05)$; a significant improvement was observed in levels of pain in Group I ( 30 days: $p<0,001)$, while in group II the results of reduction were not significant. The analysis of SF36 survey showed highly significant reduction $(p<0,001)$ of indexes in group I. At last visit, 32 ulcers were healed: 17 in the group I $(p<0,001), 11$ in the Group II $(p<0,01)$. Two-way analysis of variance (ANOVA) test was used to examine differences. Intragroup changes were evaluated with the paired Student t-test. A $p$-value of $<0.05$ was considered to be significant.

Conclusions: Lecoxen cream showed the greatest effect on the mean reduction of the lesion size and pain levels. In the patients treated with Lecoxen cream the reduction of lesion size was $70 \%-75 \%$; the reduction was smaller in the group II. At last visit, 32 ulcers were healed: 17 in the group I, 11 in the Group II. Data collected from SF36 surveys are very interesting, because they show a clear improvement in quality of life of scleroderma patients, who underwent three different treatments. In particular, a better subjective perception of tactile sensation and minor discomfort in the pathological skin have been reported. On the basis of the results, it could be argued that the medical device Lecoxen cream may be useful in the treatment of DUs in patients suffering from systemic sclerosis.

Disclosure of Interest: None declared

DOI: 10.1136/annrheumdis-2017-eular.6225

\section{THU0744-HPR ASSESSMENT OF ADALIMUMAB SUBCUTANEOUS INJECTION RELATED PAIN AND EFFECTIVENESS OF NURSE SUPPORT FOR PATIENTS WITH RHEUMATOID ARTHRITIS}

M. Fusama ${ }^{1}$, M. Suzaki ${ }^{2}$, T. Hirasawa ${ }^{3}$, M. Takemoto $^{4}$, Y. Asano ${ }^{4}$, K. Higashi ${ }^{1}$ T. Tsuru ${ }^{2}$, K. Tanimura ${ }^{5}$, M. Natsumeda ${ }^{6}$, H. Nakahara ${ }^{7} .{ }^{1}$ Division of Nursing, NTT West Osaka Hospital, Osaka; ${ }^{2}$ PS Clinic, Fukuoka; ${ }^{3}$ Division of Nursing, Hokkaido Medical Center for Rheumatic Diseases, Sapporo; ${ }^{4}$ Division of Nursing, Sweet Hospital, Kurashiki; ${ }^{5}$ Hokkaido Medical Center for Rheumatic Diseases, Sapporo; ${ }^{6}$ Sweet Hospital, Kurashiki; ${ }^{7}$ NTT West Osaka Hospital, Osaka, Japan

Background: Subcutaneous injection of biologic agents gives more freedom and independence for patients with rheumatoid arthritis (RA) than intravenous injection. Despite this, patients with RA sometimes select intravenous injections due to concerns over self-injection, such as injection anxiety, including pain, and lack of confidence in giving a self-injection [1]. It is reported that one in five people are estimated to experience injection anxiety [2]. Therefore, an understanding of subcutaneous injection pain and anxiety and support for anxiety of patients with RA are important for appropriate usage of subcutaneous biologics.

Objectives: The aim is to evaluate pain and anxiety caused by adalimumab (ADA) subcutaneous injection and assess the effectiveness of nurses' care. Methods: Patients with RA using ADA self-injections were enrolled. Pain was assessed in 4 categories: general, needle insertion, drug injection, needle removal. Pain was evaluated using Visual Analogue Scale (VAS) scale. Effectiveness of support by nurses was also assessed using self-questionnaires and free-format comments. Statistical analyses were performed utilizing Wilcoxon's signed rank test and Spearman's rank correlation coefficient.

Results: Twenty patients (Male: Female, 4: 16) completed the questionnaire. Average age and disease duration were 68 and 12.6 years, respectively. Mean \pm SD of Pain VAS were $34.9 \pm 28.1 \mathrm{~mm}$ (General), $30.3 \pm 30.6 \mathrm{~mm}$ (needle insert), $42.5 \pm 35.6 \mathrm{~mm}$ (drug injection) and $11.8 \pm 18.4 \mathrm{~mm}$ (needle removal). There were no statistically significant differences between general pain and needle insertion $(p=0.631)$, or general pain and drug injection $(p=0.121)$. However, statistically significant differences were found between general pain and needle removal $(p=0.001)$. Moreover, there were statistically significant differences between needle insertion and removal $(p=0.003)$, and drug injection and needle removal $(p=0.00048)$. General pain showed statistically significant correlation with needle insertion pain $(r=0.653, p=0.0018)$ and drug injection pain $(r=0.615, p=0.004)$. However, general pain was not correlated with needle removal pain $(r=0.137$, $\mathrm{p}=0.565$ ).

Patients with RA answered that support by nurses was effective for relieving pain $(30 \%)$, reduction of anxiety (35\%) and improving treatment motivation $(50 \%)$. According to the patients, nurses helped raise motivation by explaining that treatment prevents the progression of RA and allows many patients to feel better and have less pain. Interaction with nurses appears to be effective in reducing injection pain and anxiety and improving motivation for self-injection treatment.

Conclusions: These data indicate that needle insertion and drug injection pain have great influences on general pain. Support by nurses is likely to reduce injection anxiety and pain, resulting in higher motivation toward self-injection treatment.

References:

[1] Keininger D, et al. Health Qual Life Outcomes. 2011 Jan 13; 9:2.

[2] Nir Y, et al. Am J Trop Med Hyg 2003, 68: 341-4.

Disclosure of Interest: None declared
DOI: 10.1136/annrheumdis-2017-eular.5000

\section{THU0745-HPR A COMPARISON THE EFFECTIVENESS OF WHOLEBODY VIBRATION, PROGRESSIVE RESISTIVE EXERCISE AND HOME-BASED EXERCISE IN PATIENTS WITH KNEE OSTEOARTHRITIS}

M. Pekesen Kurtça ${ }^{1}$, U. Baş Aslan ${ }^{1}$, E. Kuyucu ${ }^{2}$. ${ }^{1}$ Physical Therapy and Rehabilitation, Pamukkale University, Denizli; ${ }^{2}$ Orthopedics and Traumatology, Medipol University, Istanbil, Turkey

Background: Knee osteoarthritis (OA) is the most common type of lower extremity OA. Systematic reviews of randomized controlled trials (RCTs) indicate that exercise therapy reduces pain and patient-reported disability in patients with knee osteoarthritis $(\mathrm{OA})$, but to date, type and the optimal exercise regimen has not been identified.

Objectives: The aim of our study was to determine the effects of whole body vibration training exercise, progressive resistive exercise, home-based exercise used in osteoarthritis treatment on pain, muscle strength, functional status and quality of life.

Methods: Fourty five patients (mean age $=53,86 \pm 5,33$ years, 43 female, 2 male) diagnosed with bilateral knee osteoarthritis (Grade II-III, Kellgren \&Lawrence) were included in this study. The assesments were performed at baseline, after third months when they completed the exercise programme and sixth months. Whole body vibration exercise training in Group-1; progressive resistive exercise training in Group-2; home-based exercise training in Group-3; were applied for three days per week, three months, totally 36 sessions. All the groups were included patient education programme at baseline. The pain was assesed according to Visual Analog Scale (VAS) and quadriceps muscle strength was evaluated by using Handheld dynamometry. The functional status of the patients was evaluated by WOMAC (Western Ontario and McMaster Universities) index and health related quality of life was evaluated by Nottingham Health Profile (NHP).

Results: Significant improvement was found after treatment on pain, quadriceps muscle strength, functional status and quality of life in all groups $(p<0.05)$. When the groups compared by ANOVA it was found that outcome measures were not significantly different between Group-1, Group-2 and Group-3 ( $p>0.05$ ).

Conclusions: Supervised resistive exercises and whole body vibration exercises were more effective in strengthening lower extremity muscles when compared to home exercise training in patients with knee OA. However, the increase in muscle strength was not observed at long- term follow- up in both groups. Neither whole body vibration exercise training programme nor progressive resistive exercise and home-based exercise programme were found to be superior for the treatment of osteoarthritis. All types of exercise training programmes were beneficial for pain, functional status, quadriceps muscle strength and quality of life. Further studies with long-term follow-up are warrented.

\section{References:}

[1] Vincent KR, Vincent HK. Resistance exercise for knee osteoarthritis. Am J Phys Med Rehabil 2012; 4 (5 0):45-52.

[2] Thomas KS, Muir KR, Doherty M, Jones AC, O'Reilly SC, Bassey EJ. Home based exercise programme for knee pain and knee osteoarthritis: randomised controlled trial. BMJ 2002; 325-752.

[3] Jordan KM, Arden NK, Doherty M, et al. EULAR Recommendations 2003: an evidence based approach to the management of kneeosteoarthritis: Report of a task force of the standing committe for international clinical studies including therapeutic trials (ESCISIT). Ann Rheum Dis 2003:62:1145-55.

[4] Li X, Wang X, Chen B, Huang L, Liu Y. Whole -body vibration exercise for knee osteoarthritis:a systematic review and meta-analysis. Evidence-Based Complementary and Alternative Medicine 2015; 1:1-11.

Disclosure of Interest: None declared

DOI: 10.1136/annrheumdis-2017-eular.6854

\section{THU0746-HPR RHEUMATOLOGY NURSE SPECIALISTS AND DMARD PRESCRIPTION - WHERE ARE WE NOW?}

M.K. Nisar ${ }^{1}$, J. Begum ${ }^{2}{ }^{1}$ Rheumatology, Luton \& Dunstable University Hospital; ${ }^{2}$ Rheumatology, Luton, Luton, United Kingdom

Background: It is widely acknowledged that a multidisciplinary team approach is the best way to care for rheumatology patient group. The rheumatology nurse specialist (RNS) is an integral part of this multidisciplinary team. EULAR has published recommendations for their role in the management of chronic inflammatory arthritis (van Eijk-Hustings $Y$ et al, 2012). The Department of Health also highlights the need for providing different models of care in a more cost effective way. It recognises that the nurse specialists' role is the bedrock of an effective care providing team and can contribute to answering the challenge of health provision in a financially difficult environment (Department of Health, 2008). Objectives: We undertook a pilot survey to understand the present climate of rheumatology practitioners' prescribing of methotrexate in their practice.

Methods: "Learning Rheum" is a national initiative with an aim to establish a core curriculum for rheumatology nursing. Prior to its national meeting, the steering committee organised a focus group discussion of an ideal training structure to be able to successfully deliver DMARD education for patients. Methotrexate was accepted as index DMARD for the purpose of the exercise. A questionnaire 
was created based on the discussion and all participants of the meeting were surveyed. Replies were compiled to ascertain the current picture of service delivery and educational training.

Results: 25 rheumatology specialist nurses participated in the exercise. Their job experience ranged from one week to 25 years (median 7 years). $21 / 25$ (84\%) ran independent clinics. 16/25 (64\%) were employed at band 6 . Five (20\%) did not feel confident in counseling patients initiating methotrexate. Apart from two, no one had any formal training in delivering DMARD education. 10/25 (40\%) had never been supervised whilst undertaking an educational session for patients. Six (24\%) did not feel confident to teach or supervise their peers.

Conclusions: This is a pioneering survey mapping the training of rheumatology practitioners and nurse specialists to service delivery. This initiative highlights a wide variation in the training structure of a key job provision. There is lack of formal induction programme. Despite most participants running independent clinics and providing DMARD education for years, they confessed to have no formal education and little supervision. Over a fifth did not feel confident in counseling patients commencing methotrexate despite being in the job for a median of 18 months. Though most centres are delivering contemporary services, these are not being used effectively for developing key team members. A quarter of the cohort felt unprepared to impart the skills to peers (median experience 1 year).

In conclusion, there is wide variation in the training of rheumatology nurse specialists. This can potentially have a negative impact on a relatively young workforce. There is a need for improving training standards to help deliver good quality rheumatology professionals of the future.

Disclosure of Interest: None declared

DOI: 10.1136/annrheumdis-2017-eular.2783

\section{THU0747-HPR EFFECT OF DIFFERENT PHYSICAL THERAPY PROGRAMS ON PAIN, STRENGTH AND FUNCTIONAL SITUATIONS ON KNEE OSTEOARTHRITIS}

\section{Ö.E. Günaydın, V. Bayrakcı Tunay. Sports Physiotherapy, Hacettepe University,}

\section{Ankara, Turkey}

Background: Knee Osteoarthritis $(\mathrm{OA})$ is one of the most common causes of disability with an increasing prevalence and incidence with age. Although there are studies in the literature that examine the efficacy of ESWT, Kinesio taping and exercise on knee OA, there is no study to compare these methods with each other.

Objectives: The purpose of this study is to compare the effects of Extracorporeal Shockwave Therapy (ESWT), Kinesio taping and exercise therapy on pain, knee strength and functional situations of patients with knee osteoarthritis (OA)

Methods: Forty eight female patients aged between 50-65 and previously diagnosed with a grade 1-3 (Kellgren-Lawrence scale) knee OA included in this study. Patients were assessed before treatment and after treatment at 6 weeks and at 12 weeks. Visual Analog Scale, (VAS), (ISOMED ${ }^{\circledR} 2000$ D\&R $\mathrm{GmbH}$, Germany) isokinetic device, Timed Up and Go test (TUG) and WOMAC scale were carried out for assessing patients' pain, knee strength and functional situations. After randomising the patients into 3 different groups, the first group received 1 session of ESWT per 6 weeks, the second group received 2 sessions of Kinesio tape per 6 weeks and the third group was prescribed with an exercise program only.

Results: The between-groups results showed a significant improvement for the pain during night, pain during resting, and WOMAC test in the exercise group $(p<0,05)$, while no difference was found for the other measurements $(p>0,05)$. The inter-groups results showed significant improvements in 3 of the groups $(p<0,05)$, while there was no difference in 60 degrees/sec isokinetic quadriceps strength test in the Kinesio taping group and TUG test in the ESWT group.

Conclusions: The results of this study showed that; ESWT, Kinesio tape and exercise therapies are all effective in decreasing pain intensity, improving knee strength and functional status levels of patients with knee OA and can be used as alternative approaches to treat symptoms of knee OA.

\section{References:}

[1] Plotnikoff, R., Karunamuni, N., Lytvyak, E., Penfold, C., Schopflocher, D., Imayama, I. ve diğerleri. (2015) Osteoarthritis prevalence and modifiable factors: a population study. BMC Public Health, 15, 1195.

[2] Sarzi-Puttini, P., Cimmino, M.A., Scarpa, R., Caporali, R., Parazzini, F., Zaninelli, A. ve diğerleri. (2005). Osteoarthritis: an overview of the disease and its treatment strategies [Bildiri].Seminars in arthritis and rheumatism.

[3] De Oliveira Melo, M., Aragão, F.A.,Vaz, M.A. (2013) Neuromuscular electrical stimulation for muscle strengthening in elderly with knee osteoarthritis-a systematic review. Complementary therapies in clinical practice, 19 (1), 27-31.

[4] Zhao, Z., Jing, R., Shi, Z., Zhao, B., Ai, Q.,Xing, G. (2013) Efficacy of extracorporeal shockwave therapy for knee osteoarthritis: a randomized controlled trial. Journal of surgical research, 185 (2), 661-666.

Disclosure of Interest: None declared

DOI: 10.1136/annrheumdis-2017-eular.5437

\section{THU0748-HPR RECOMMENDATIONS ON PHYSICAL THERAPY PRESCRIPTION FOR AXIAL SPONDYLOARTHRITIS IN THE NETHERLANDS}

S. van Weely ${ }^{1}$, F. van der Giesen ${ }^{1}$, N. Lopuhaa ${ }^{2}$, F. van Gaalen ${ }^{3}$, T. Vliet Vlieland ${ }^{1} .{ }^{1}$ Orthopaedics, Rehabilitation and Physical Therapy, Leiden University Medical Center, Leiden; ${ }^{2}$ Dutch Arthritis Foundation, Amsterdam;

${ }^{3}$ Rheumatology, Leiden University Medical Center, Leiden, Netherlands

Background: In national and international guidelines physical therapy, comprising exercise interventions and education, is recommended as a required treatment modality for the optimal treatment of axial spondyloarthritis (axSpA). [1-3] However, specific details regarding referral for physical therapy and optimal content and dose of exercise interventions are lacking. Research showed large variation in the content of exercise therapy in axSpA patients, which reflects suboptimal care [4]

Objectives: To develop practice recommendations on indications for referral, content, dose and safety aspects of exercise therapy for axSpA patients based on scientific evidence, expert opinion and patient values. The ultimate aim is improving the quality of exercise therapy care for people with axSpA.

Methods: The recommendations are based on scientific evidence, expert opinion and patient values and were formulated following a combination of literature review and three expert-group meetings (consisting of patients, rheumatologists, physical and exercise therapists, policy makers, scientists and special interest groups). In three consecutive expert-meetings clinically relevant questions, draft recommendations based on systematic literature reviews, and final recommendations including level of agreement were generated. Lastly, a field consultation among physical and exercise therapists, rheumatologists, scientists and special interest groups will be scheduled and an implementation strategy, comprising of an information intervention and directives, will be developed.

Results: In the first expert-group meeting 18 clinically relevant questions were formulated, on: indication and referral, assessment, content of treatment, evaluation and safety. In addition to recently published systematic reviews, additional literature reviews concerned assessment, safety and the dosage of exercise therapy. Related to the clinical questions, a framework for the therapeutic process and 12 draft recommendations were developed and discussed in the second meeting. In the third and last meeting the 12 recommendations regarding the delivery of physical therapy and exercise interventions were set and the level of agreement was determined.

Conclusions: The expert-meetings and literature searches led to 12 practice recommendations and a clear starting point for the development of the implementation strategy. Twelve practice recommendations regarding the delivery of physical therapy for patients with axSpA were developed, based on scientific evidence, expert opinion patient values. The field testing and development and execution of a dissemination and implementation strategy will be done in 2017 .

References:

[1] Dagfinrud $\mathrm{H}$, et al. Physiotherapy interventions for ankylosing spondylitis. Cochrane Database Syst Rev. 2008

[2] van der Heijde D, et al. 2016 update of the ASAS-EULAR management recommendations for axial spondyloarthritis. Ann Rheum Dis. 2017.

[3] Steeringgroup recommendations Spondyloartritis, Dutch Rheumatology Association, Guidelines for diagnosis and treatment of axial Spondyloartrtis, 2014.

[4] Van der Giesen et al. Use and content of physical and (group)exercise therapy for people with axial spondylarthritis, NVR congress, posterpresentation, 2016. Acknowledgements: The Dutch Arthritis Foundation financially supported this project.

Disclosure of Interest: None declared

DOI: 10.1136/annrheumdis-2017-eular.4432

\section{THU0749-HPR INCREASING PHYSICAL ACTIVITY IN PEOPLE WITH A CHRONIC DISEASE: EXAMINING THE EFFECTIVENESS OF A MOTIVATIONAL AND A PLANNING INTERVENTION, THEIR INTERACTION AND VARIOUS POTENTIAL MODERATORS AND MEDIATORS}

S. Hilberdink ${ }^{1}$, G.-J.Y. Peters ${ }^{2} .{ }^{1}$ Allied Healthcare Centre for Rheumatology and Rehabilitation, Groningen; ${ }^{2}$ Psychology and Education Science, Open University of the Netherlands, Heerlen, Netherlands

Background: Physical activity has many health benefits, especially in people with a chronic disease. Behaviour change interventions appear more effective than just advice when increasing physical activity. However, most studies that compare different interventions overlook interaction effects between methods and their parameters for effectiveness.

Objectives: Present study examined the effectiveness of a motivational and an action planning intervention for increasing physical activity in patients with a chronic disease. Their interaction as well as various potential moderators and mediators were studied in order to identify which intervention is effective in which patients.

Methods: In a healthcare centre specialised in the treatment of people with a chronic disease, participants whose physiotherapist would advise them to be more physically active were randomly assigned to one of four interventions in a factorial design: 1) a control condition with only advice, 2) a motivational intervention 